O ano de 2021 se inicia e o mundo ainda está vivendo a pandemia da Covid19, com quase 2 milhões de vidas perdidas, após um ano do primeiro caso informado. No Brasil, passamos a barreira dos 200 mil mortos, a situação ainda se apresenta de maneira muito instável e somos, atualmente, o segundo país com mais mortes pela doença registradas. No entanto, a esperança chega com o início da vacinação para os idosos e profissionais da saúde que trabalham na linha de frente dos hospitais, em contato direto com os infectados pelo vírus SARS-CoV-2.

$\mathrm{Na}$ UFSC, as atividades administrativas e acadêmicas continuam em formato remoto, com a manutenção do distanciamento social para a segurança de todos. As dificuldades e os desafios são inúmeros, mas professores de todos os níveis, da educação básica à superior, têm encontrado estratégias para diminuir ao máximo as distâncias e, assim, aproximar seus alunos da escola e da universidade.

Para a Revista Perspectiva, 2021 traz mudanças importantes. Após meses de preparação, um novo formato de publicação foi adotado pela revista, para que o fluxo dos artigos submetidos - que é intenso - seja agilizado. Assim, a revista adota, a partir de janeiro desse ano, a Publicação Contínua (PC), com a abertura e fechamento conjunto de seus 4 números, no início e final do ano, consecutivamente.

O principal objetivo desse novo formato é dar celeridade ao fluxo de trabalho, disponibilizando os trabalhos com maior rapidez para pesquisadores, estudantes e leitores, de maneira digital e com acesso livre. Com isso, a Revista reitera seu princípio de que tornar gratuito o acesso a pesquisas gera um maior intercâmbio global de conhecimento, conforme o Public Knowledge Project, "iniciativa multiuniversitária para melhorar a qualidade e o alcance da publicação acadêmica".

Assim, compõem esse número o dossiê APPrendizagem na Era Digital: (re)conhecimentos em contexto escolar, organizado pela professora Juliana Cristina Faggion Bergmann, da Universidade Federal de Santa Catarina (UFSC), além de 20 artigos de demanda contínua.

O primeiro artigo, intitulado $O$ paradigma da complexidade: contexto e fundamentos na formação docente, de Greice Scremin e Silvia Maria de Aguiar Isaia, do Centro Universitário Franciscano, se propõe a discutir conceitos desenvolvidos por Edgar Morin e suas implicações para a formação docente, a partir de uma análise qualitativa de obras do filósofo e pesquisador francês.

Ainda com o olhar sobre o docente, o segundo artigo, intitulado Precarização do trabalho e adoecimento docente em contextos de multicampia: um estudo de 
caso sobre docentes substitutos da Universidade do Estado da Bahia - UNEB, os autores Liane Nascimento dos Santos e Jailson Braga Brandão, da Universidade do Estado da Bahia (UNEB), apresentam os resultados de um estudo de caso com professores daquela universidade acerca das suas condições de trabalho e chamando a atenção para a temática da precarização do trabalho docente e dos adoecimentos por ela desencadeados.

O trabalho docente na Educação Infantil é tratado no terceiro texto, Em defesa da atividade de professores e crianças: reflexões sobre a iniciação às ciências na educação infantil, de Tatiana Schneider Vieira de Moraes, Elieuza Aparecida de Lima, ambas da Universidade estadual Paulista (UNESP), e Anna Maria Pessoa de Carvalho, da Universidade de São Paulo (USP), em que as autoras analisam os desafios e especificidades do trabalho docente na Educação Infantil a partir do recorte da Iniciação às Ciências.

O quarto artigo, de Margarete Sacht Góes, da Universidade Federal do Espírito Santo (UFES), intitulado Experiências estéticas e estésicas: a leitura de imagens na educação infantil, também discute sobre a Educação Infantil e utiliza o método de Robert William Ott (1989) para refletir sobre o trabalho com a leitura de imagens nessa fase de formação e busca compreender com Lev Vigotski (2000) o processo de apropriação artístico-cultural na infância.

A primeira infância também é o foco de estudo do quinto artigo, Interações e desenvolvimento da fala na abordagem histórico-cultural: o contexto da creche, das autoras Arlene Araujo Nogueira e Michelle de Freitas Bissoli, da Universidade Federal do Amazonas (UFAM), que analisa o desenvolvimento da fala em crianças em idade pré-escolar, entre um e dois anos, a partir de observações participativas de interações cotidianas das crianças e suas professoras, diretas ou mediadas por objetos.

Na mesma área da educação pré-escolar, o artigo seguinte, A educação infantil e a pedagogia dos multiletramentos, de Wagno da Silva Santos e Acir Mário Karwoski, da Universidade Federal do Triângulo Mineiro (UFTM), pretende discutir as contribuições da Pedagogia dos Multiletramentos para a formação continuada de professores para o uso das tecnologias digitais de informação e comunicação (TDIC) na Educação Infantil.

O letramento digital é também tema do sétimo artigo, de Jocenildes Zacarias Santos e Márcia Tereza Fonseca Almeida, da Universidade do Estado da Bahia (UNEB) e de Sidneya Magaly Gaya, da Universidade Federal de Santa Catarina (UFSC). $O$ texto Letramento digital no contexto da educação de jovens e adultos: tecendo redes de conhecimentos para o processo ensino-aprendizagem se propõe a compreender as contribuições do letramento digital tem para o processo ensino-aprendizagem da EJA, apontando como resultado o potencial das tecnologias como auxiliar 
Cássia Cristina Furlan, Universidade Federal da Grande Dourados (UFGD), discute o lugar do jogo na formação de futuros professores no texto Corpos, gênero e performances em cena: entrelaçar entre RPG e experiências na constituição das identidades. Nele a autora analisa de maneira qualitativa questões de gênero e sexualidade que emergem de atividades com o RPG.

Também analisando questões do corpo, o nono artigo, intitulado Corporeidade e cuidado: uma colcha possível na formação?, de Denise Consuelo Moser Aguiar e Gelson Aguiar da Silva Moser, da Universidade Federal da Fronteira Sul (UFFS) e Rosane Gonçalves Nitschke, da Universidade Federal de Santa Catarina (UFSC), pretende debater a corporeidade e o cuidado na formação das alunas do curso de enfermagem, em um estudo etnográfico e ressaltando a importância da prática formativa para esse processo.

Mozart Linhares da Silva e Betina Hillesheim, da Universidade de Santa Cruz do Sul (UNISC) problematizam a crise da verdade na contemporaneidade e suas relações com a constituição de um ethos do fascismo e suas implicações na educação no artigo "Jogos de verdade", educação e o ethos do fascismo contemporâneo, que analisa as condições para o dizer verdadeiro a partir da perspectiva de Michel Foucault.

O texto Interfaces entre educação e comunicação: pontos de intersecção concentra-se na problematização da interface entre educação e comunicação. Os resultados obtidos pelos autores Ricardo Cocco, da Universidade Federal de Santa Maria - Campus Frederico Westphalen, e Flávia Eloisa Caimi, da Universidade de Passo Fundo, apontam a atual centralidade das mídias na vida dos indivíduos, o que inclui os processos educativos.

Um instrumento de pesquisa em educação é explorado por Giovana Scareli, da Universidade Federal de São João del-Rei, no artigo Os cadernos de anotações de Guimarães Rosa e de Eduardo Coutinho: algumas aproximações com a pesquisa em Educação. Nele a autora desenvolve uma pesquisa bibliográfica para analisar os cadernos de anotações de Guimaraes Rosa e Eduardo Coutinho e reflete sobre a importância desse instrumento para a pesquisa em educação, além de uma possível interface com as artes e a literatura.

O décimo-terceiro artigo desse número também olha para a arte e a traz como ponto de interseção com a educação. O texto Que Desenho ensinar para os(as) normalistas em formação? Uma contribuição do maranhense Arthur Marinho (primeira metade do século XX), de Marcos Denilson Guimarães e Maria Consuelo Alves Lima, da Universidade Federal do Maranhão (UFMA), se propõe a analisar a disciplina de desenho na formação de professores primários na cidade de São Luís (MA) na primeira metade do século XX, a partir da trajetória de Arthur Marinho. 
No décimo-quarto artigo, Globalização e neoliberalismo na crise estrutural do capital: rebatimentos na educação, José Deribaldo Gomes dos Santos, da Universidade Estadual do Ceará (UECE), e Maria Escolástica de Moura Santos, da Universidade Federal do Piauí (UFPI), baseiam-se no Materialismo Histórico e Dialético para explicar a crise do capitalismo contemporâneo, organizando sua exposição em quatro momentos.

Giovani Ferreira Bezerra, da Universidade Federal da Grande Dourados UFGD, aborda igualmente o tema do neoliberalismo, apresentando uma leitura crítica do processo de inclusão escolar de pessoas com deficiência no artigo Neoliberalismo e formulações pedagógicas recentes: o ideário inclusivista em educação.

Os 20 Anos do Artigo 170 de Santa Catarina - precursor das Políticas de Ação Afirmativa na Educação Superior brasileira, de André Dias e Stela Maria Meneghel, ambos da Fundação Universidade Regional de Blumenau, falam de um tema fundamental em nossa área, quando debatem a democratização da Educação Superior no Brasil a partir de políticas de acesso e permanência, como a Lei de Cotas. Para isso, analisam o programa de bolsas do Artigo 170 da Constituição do Estado de Santa Catarina (1989), identificando seus pontos positivos e seus desafios.

Dentro da temática de políticas públicas, Andrea Barbosa Gouveia, da Universidade Federal do Paraná (UFPR), Domingos Savio Abreu, da Universidade Federal do Ceará (UFC) e Gabriela Schneider, também da Universidade Federal do Paraná (UFPR) analisam as condições materiais e de infraestrutura de escolas do Paraná frequentadas por participantes do Programa Bolsa Família, no artigo As diferenças na garantia do direito à infraestrutura escolar no Paraná: um estudo nas escolas de ensino médio com beneficiários do Programa Bolsa Família. Nele as autoras tentam compreender se as condições de oferta das escolas são equânimes em escolas de ensino médio com diferentes percentuais de estudantes do programa, utilizando-se para isso de 7 indicadores e 40 variáveis.

O décimo-oitavo texto desse número faz um Estado da arte em pesquisas acadêmicas brasileiras, de 2010 a 2019, sobre o ensino de geometria desenvolvidas no Nordeste, apresentado pelas autoras da Universidade Estadual do Ceará (UFC) Marcilia Chagas Barreto, Zelia Beserra Camelo, Nassara Maia Cabral Cardoso Gomes e Gabrielle Andrade Pereira. A partir de uma pesquisa bibliográfica as autoras debatem a pouca presença do ensino da geometria nas pesquisas acadêmicas da área de Matemática.

No penúltimo artigo de demanda contínua, intitulado Youtube e educação matemática: um estudo dos canais especializados em ensinar matemática escolar, Débora de Lima Velho Junges, do Instituto Federal Catarinense (IFC), Lucas Pereira da Rosa, da Universidade Feevale e Amanda Gatti, do Instituto Federal Catarinense (IFC), também se interessam pela área de Matemática, a partir 


\section{Editores Científicos}

Juliana Cristina Faggion Bergmann

David Antonio da Costa

Diana Carvalho de Carvalho

Eliane Santana Dias Debus

Patricia Laura Torriglia da análise dos 05 canais brasileiros do Youtube com maior número de inscritos que se dedicam ao ensino de conteúdos dessa área.

Finalmente, no artigo que encerra esse número, a área de Matemática continua sendo o foco de interesse, com o texto de Maria Célia Leme da Silva, da Universidade Federal de São Paulo (UNIFESP), intitulado Wentworth \& Hill e Heitor Lyra da Silva: circulação e apropriação de uma geometria intuitiva em que a autora analisa a circulação e apropriação de propostas educacionais internacionais para o ensino de geometria.

\section{Referências}

OTT, Robert William. Aprendendo a olhar: a educação orientada pelo objeto em museus e escolas. São Paulo: MAC, 1989.

Public Knowledge Project. Disponível em: https://pkp.sfu.ca/

SANTA CATARINA. Constituição do Estado de Santa Catarina (1989). Florianópolis: SC, 2009. Disponível em: http://www.uniedu.sed.sc.gov.br/index.php/legislacao/leis-edecretos-legislacao/96-constituicao-estadual-de-santa-catarina-de-1989/file

VIGOTSKI, Lev Semenovich. A construção do pensamento e da linguagem. Tradução de Paulo Bezerra. São Paulo: Martins Fontes, 2000. 